\title{
Criteria Weighting and 4P's Planning in Marketing Using a Fuzzy Metric Distance and AHP Hybrid Method
}

\author{
Tuncay Gürbüz \\ Industrial Engineering Dept., Galatasaray University, Çıră̆an cad. No.36 34357 \\ Ortaköy, Istanbul, Turkey,tuncaygurbuz09@gmail.com, \\ Y.Esra Albayrak \\ Industrial Engineering Dept., Galatasaray University, Çıră̆an cad. No.36 34357 \\ Ortaköy, İstanbul, Turkey, ealbayrak@gsu.edu.tr \\ Elif Alaybeyoğlu \\ Industrial Engineering Dept., Galatasaray University, Çıră̆an cad. No.36 34357 \\ Ortaköy, Istanbul, Turkey, ealaybeyoglu@gsu.edu.tr
}

Received 16 December 2012

Accepted 1 July 2013

\begin{abstract}
Production and consumption relationship shows that marketing plays an important role in enterprises. In the competitive market, it is very important to be able to sell rather than produce. Nowadays, marketing is customeroriented and aims to meet the needs and expectations of customers to increase their satisfaction. While creating a marketing strategy, an enterprise must consider many factors. Which is why, the process can and should be considered as a multi-criteria decision making (MCDM) case. In this study, marketing strategies and marketing decisions in the new-product-development process has been analyzed in a macro level. To deal quantitatively with imprecision or uncertainty, fuzzy sets theory has been used throughout the analysis.
\end{abstract}

Keywords: Marketing Strategy Selection, MCDM, AHP, Fuzzy Metric Distance

\section{Introduction}

Nowadays the development of technology and the supply which exceeds demand create difficult conditions in the market and competition. The companies that aim to provide competitive advantage tend towards new products and new markets to satisfy customer needs because a company without satisfied customers has not a chance for success in long term. Thus, the New Product Development (NPD) process becomes more and more important. NPD is not only producing a new product but also having new target markets/segments and new positioning with an existing product. NPD process consists of customer needs analysis, idea generation, screening and evaluation, business analysis, product and marketing strategy development, testing and commercialization steps ${ }^{1}$. Marketing is the process of planning and executing the conception, pricing, promotion, and distribution of ideas, goods, and services to create exchanges that satisfy individual and organizational goals and consequently marketing strategy is a critical component of $\mathrm{NPD}^{2,3}$.

Actually NPD depends on the point of view of both the company and its customers. There are six options related to the newness of the products ${ }^{4}$;

- New-to-the-World Products, involves an innovation and creation of a new market,

- New Product Lines, represent new offerings by the company to an established market,

- Product Line Extensions, supplement of an existing product with new styles, models, features or flavors etc.

- Improvements or Revisions of Existing Products, offers improved performance or greater perceived value, 
- Repositioning, involves targeting existing products at new markets and segments,

- Cost Reductions, offering performance similar to competing products with lower price.

After analyzing customer needs, these options are being evaluated regarding the stage of the product in its life cycle aiming a successful mature stage. Furthermore, the marketing strategy is planned considering the options. Every option requires an appropriate Marketing Mix (MM). MM is probably the most famous marketing term, which a set of marketing tools that work together to satisfy customer needs and build customer relationships ${ }^{5}$. Its elements are the basic, tactical components of a marketing plan. MM does provide a handy framework for marketing analysis. The tactical section of a marketing plan summarizes how the business intends to use each element of the MM. Also known as the $4 \mathrm{P}^{\prime} \mathrm{s}$, the $\mathrm{MM}$ elements are price, place, product, and promotion.

The first $\mathrm{P}$ is the price of the product and decisions surrounding the overall pricing strategies of company. Pricing is the process of determining what a company will receive in exchange for its products. Place is also known as channel, distribution, or intermediary. It is the mechanism through which goods and/or services are moved from the manufacturer/ service provider to the user or consumer. Product is simply the tangible, physical entity that they may be buying or selling. This should define the characteristics of the product or service that will meet customers' needs of the target segment. Promotion includes all of the tools available to the marketer for marketing communication. This may include advertising, personal selling, sales promotions and public relations.

For a company, decisions concerning marketing strategy determination depend on determinants in the market as well as the consumer portfolio or the target market of the company, the financial and organizational structure of the company itself and the characteristics of the product. Therefore, it is a multi-criteria decision making (MCDM) problem. In this study, the criteria that are effective in marketing strategies and marketing decisions in the NPD process will be defined and analyzed at a macro level i.e. all the sub-criteria that can be effective in this decision process will not be included in this stage of the study and all the criteria are supposed to be independent. In the literature, during the last years, many studies have been published about marketing strategy selection and strategic marketing; by Rekik et al., proposing a multi-criteria decision making support system to aid the marketing strategy selection in e-commerce ${ }^{6}$, by Lin et al., implementing fuzzy analytic network process for the selection of the best marketing strategy as a multiple criteria decision making problem ${ }^{7}$, by $\mathrm{Wu}$ et al., modeling the marketing strategy decisionmaking problem as a multi-criteria decision-making problem, implementing of the integration of the Analytic Network Process (ANP) and TOPSIS to determine the appropriate marketing strategy ${ }^{8}$, by Lin \& Lee, investigating the use of multi-agent based hybrid intelligent systems in support of international marketing planning ${ }^{9}$, by Wierenga, formulating interesting and relevant research questions about marketing decision making $^{10}$, by Tsai et al., proposing an integrated model for evaluating airlines' websites effectiveness which is based on the perspectives of "marketing mix 4Ps" and "website quality" for the web-based marketing using the $\mathrm{ANP}^{11}$, by Liao, proposing a method that will guide the product development team to select the best marketing strategy by taking into account the price level and product/market segmentation ${ }^{12}$, and by Wang, providing a reference for planning brand marketing with a hybrid MCDM model combining the Decision Making Trial and Evaluation Laboratory (DEMATEL) with ANP and VIKOR methods ${ }^{13}$.

A novel hybrid MCDM model will be proposed to develop optimal marketing-mix plans weigh the criteria and to define the best strategic marketing scenario in dynamic competitive markets. Analytically, decisionmakers are asked to express their opinions on comparative importance of various factors in linguistic terms. Since the crisp values are inadequate to model real-life situations where human perception is a factor, these linguistic variable scales, such as "high", "medium" and "low", are then converted into fuzzy numbers.

As opposed to regular applications of fuzzy AHP, in this study there will not be a defuzzification step and final fuzzy weights for the alternatives of the model will be ranked using a fuzzy metric distance method. To evaluate, compare or choose the best alternative, ranking of fuzzy numbers is an important component of 
the decision making process. In this paper we used a fuzzy number ranking method. This method identifies and uses a distance between the centroid and original points to rank fuzzy numbers and based on distance between fuzzy sets, weighted mean value, coefficient of variation and centroid point.

The originality of the study is due to the originality of the hybrid method and the fact that it is the first time for its application to marketing strategy selection.

The study is organized as follows: Basic concepts of marketing strategy will be explained in Section 2 . Section 3 gives the preliminary information about the methods used to build the hybrid method and the methodology. Section 4 gives the proposed model to select the appropriate marketing strategy. A numerical illustration will be given in Section 5 and finally the concluding remarks will be given in Section 6 .

\section{Basic Concepts of Marketing Strategy}

In order to propose a marketing strategy selection model, marketing and marketing strategy should be defined. The essence of marketing is a transaction - an exchange - intended to satisfy human needs and wants $^{14}$. Marketing is not just an activity of a department in a company; it is a management requiring process. Marketing consists of five main steps ${ }^{15}$ :

- research,

- segmentation, market targeting, positioning,

- marketing mix constitution,

- implementation of the strategy and

- control.

The second and the third steps form the marketing strategy. Marketing strategy involves two key questions: Which customers will the company serve? How to create a value for these customers?

Marketing strategy starts with segmentation. Segmentation is to find customer groups which are homogeneous between them and heterogeneous compared to other groups ${ }^{16}$. Segmentation aims to find the distinctive qualities of current markets, divide markets into segments according to these qualities, determine the size and the growth of these segments and observe the competitors.
Next comes the market targeting. Basically the target market is the segment served. The target market must be clearly identifiable to simplify the marketing communications and large enough to achieve required profit. A company might consider five basic strategies for target market selection ${ }^{4}$ :

- single segment targeting,

- selective targeting,

- mass market targeting,

- product specialization,

- market specialization.

Once the target market is defined, the company must consider creating a value for its customers. This step is called positioning. A position is a complex set of perceptions, impressions and feelings and it is important to note that customers position the company's value offering with or without its help ${ }^{17}$. Positioning step is more important for the new products because once a product is positioned for the customer, it is nearly impossible to change.

Last step of the marketing strategy is creating the marketing mix. Marketing mix elements, also known as 4P's, are product, price, promotion and place ${ }^{18}$. Each $\mathrm{P}$ represents different strategies for marketing and is vital for the success. It is a framework which helps to structure the approach to each market. The mix is a bundle of variables which are offered to the customer.

\section{Methodology}

\subsection{Analytic Hierarchy Process - AHP}

AHP is a very well known and widely used MCDM method proposed by Saaty ${ }^{19}$. It is a theory of measurement that has been extensively applied in modeling the human judgment process. It decomposes a complex decision into a multi-level hierarchical structure enabling people to effectively combine both measurable and subjective factors in the decision process.

When we take a look for the last ten years, as before, we can see that AHP is being used in various fields such as supplier selection ${ }^{20}$, tissue engineering ${ }^{21}$, firm's performance evaluation $^{22}$, hydrogen production method selection $^{23}$, military personnel assignment ${ }^{24}$, maintenance strategy selection ${ }^{25}$, and macro$\operatorname{ergonomics}^{26}$. 
There are many fuzzy AHP methods proposed by various authors. These methods are systematic approaches to the alternative selection and justification problem by using the concepts of fuzzy set theory and hierarchical structure analysis. The earliest work in fuzzy AHP appeared in Ref.27, which extend Saaty's AHP to deal with the imprecision and subjectivity in the pairwise comparison precision. They compared fuzzy ratios described by triangular membership functions. Buckley ${ }^{28}$ determined fuzzy priorities of comparison ratios whose membership functions are trapezoidal. Stam et al. ${ }^{29}$ explored how recently developed artificial intelligence techniques can be used to determine or approximate the preference ratings in AHP. They conclude that the feed-forward neural network formulation appears to be a powerful tool for analyzing discrete alternative multi-criteria decision problems with imprecise or fuzzy ratio-scale preference judgments. Chang ${ }^{30}$ introduced a new approach for handling fuzzy AHP, with the use of triangular fuzzy numbers for pairwise comparison scale of fuzzy AHP, and the use of the extent analysis method for the synthetic extent values of the pairwise comparisons. Ching-Hsue ${ }^{31}$ proposed a new algorithm for evaluating naval tactical missile systems by the fuzzy analytical hierarchy process based on grade value of membership function. Cheng et al. ${ }^{32}$ proposed a new method for evaluating weapon systems by AHP based on linguistic variable weight. Zhu et al..$^{33}$ made a discussion on the extent analysis method and applications of FAHP.

In this study, pairwise comparison process remaining the same as in AHP, there won't be a defuzzification process as opposed to the models mentioned above. The fuzzy weights of the alternatives will be calculated and then the Fuzzy Metric Distance method explained in the next section will be used in order to rank the alternatives.

One has to note that this could also be done with a defuzzification process or a comparative study for further research is also possible. In that case, any defuzzification method, such as center of gravity or center of largest area etc., which is appropriate to the data at hand can be chosen arbitrarily. However, this is a proposed "alternative" method in order to form a marketing strategy using fuzzy AHP and fuzzy Metric Distance method.

\subsection{Ranking Fuzzy Numbers with Fuzzy Metric Distance Method}

In this section, we present Cheng's method ${ }^{34}$ for ranking fuzzy numbers based on metric distance method. Cheng's method use the inverse functions of the left and the right membership functions to calculate the metric distance and this method can use in negative and positive ranking of fuzzy numbers.

The distance method is based on calculating the centroid point, where the distance means the Euclidian distance $d_{\varepsilon}$ from original point to the centroid point $\left(\overline{x_{0}}, \overline{y_{0}}\right)$ which is the geometric center of a fuzzy number $\tilde{A}=(l, m, u)$ with the membership function defined as follows:

$$
\mu_{\tilde{A}}(x)=\left\{\begin{array}{cc}
f_{\tilde{A}}^{L}(x)=\frac{x-l}{m-l} & l \leq x \leq m \\
f_{\tilde{A}}^{R}(x)=\frac{x-u}{m-u} & m \leq x \leq u \\
0 & \text { otherwise }
\end{array}\right.
$$

With $g_{\widetilde{A}}^{L}$ and $g_{\tilde{A}}^{R}$ the inverse functions of $f_{\tilde{A}}^{L}$ and $f_{\tilde{A}}^{R}$ respectively, the centroid point for $\widetilde{A}$ is defined as follows:

$$
\left\{\begin{array}{l}
\overline{x_{0}}(\tilde{A})=\frac{\int_{l}^{m} x f_{\tilde{A}}^{L}(x) d x+\int_{m}^{u} x f_{A}^{R}(x) d x}{\int_{l}^{m} f_{\tilde{A}}^{L}(x) d x+\int_{m}^{u} f_{\tilde{A}}^{R}(x) d x} \\
\overline{y_{0}}(\tilde{A})=\frac{\int_{0}^{1} y g_{\tilde{A}}^{L}(y) d y+\int_{0}^{1} y g_{\tilde{A}}^{R}(y) d y}{\int_{0}^{1} g_{\tilde{A}}^{L}(y) d y+\int_{0}^{1} g_{\tilde{A}}^{R}(y) d y}
\end{array}\right.
$$

The $\overline{\mathrm{x}_{0}}$ is the same as Murakami et al.' $\mathrm{s}^{35}$ definition whereas $\overline{y_{0}}$ is derived from the inverse functions.

The advantage of this method is being able to rank more than two fuzzy numbers simultaneously and to handle the fuzzy numbers that are not normal. The distance is calculated with the following formula:

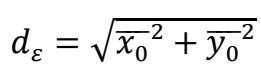

The ranking depends on the following rule: Greater the distance from the origin, greater the fuzzy number.

However one has to keep in mind the cases where two fuzzy numbers have the same centroid point. One such case is represented in the following figure where $\widetilde{\mathrm{A}_{1}}=\left(\mathrm{l}_{1}, \mathrm{~m}_{1}, \mathrm{u}_{1}\right)$ and $\widetilde{\mathrm{A}_{2}}=\left(\mathrm{l}_{2}, \mathrm{~m}_{2}, \mathrm{u}_{2}\right)$. 


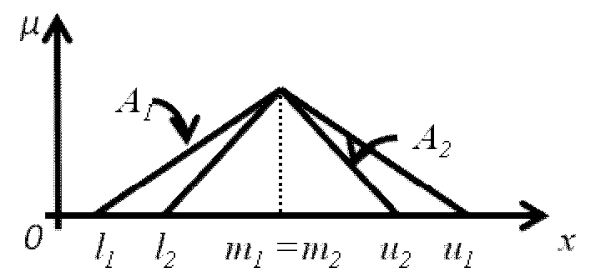

Fig. 1. Two fuzzy numbers having identical centroid points

In those cases where the centroid point of two different fuzzy numbers are the same, then the tie breaking will be handled with the coefficient of variation (CV) method proposed by Cheng ${ }^{34}$.

The CV method uses the generalized mean and standard deviation as defined in Ref.36. In their study, they assume two kinds of probability distributions, namely uniform and proportional, for fuzzy events and derive corresponding indices accordingly. In this study, uniform distribution is used and appropriate indices are presented in equation (4).

$$
\left\{\begin{array}{c}
\bar{x}(\tilde{A})=\frac{\int_{S(\widetilde{A})} x \mu_{\widetilde{A}}(x) d x}{\int_{S(\widetilde{A})} \mu_{\widetilde{A}}(x) d x} \\
\sigma(\tilde{A})=\left[\left(\frac{\int_{S(\widetilde{A})} x^{2} \mu_{\widetilde{A}}(x) d x}{\int_{S(\widetilde{A})} x \mu_{\widetilde{A}}(x) d x}\right)-\left(\overline{x_{U}}(\tilde{A})\right)^{2}\right]^{1 / 2}
\end{array}\right.
$$

For triangular fuzzy numbers, these equations can be represented as in equation (5) for uniform distribution.

$$
\left\{\begin{array}{c}
\bar{x}(\tilde{A})=\frac{1}{3}(l+m+u) \\
\sigma(\tilde{A})=\frac{1}{18}\left(l^{2}+m^{2}+u^{2}-l m-l u-m u\right)
\end{array}\right.
$$

$\mathrm{Cheng}^{24}$ proposed an index that overcomes the drawbacks of the method proposed by Lee an $\mathrm{Li}^{36}$ : it is not easy to compare the orderings clearly when cases like high (resp. low) mean value at the same time high (resp. low) spread presents themselves. CV is defined as follows and expresses the standard deviation as a percentage of the mean:

$$
C V=\sigma / \bar{x}
$$

The CV index method states that the smaller the CV value the higher ranked a fuzzy number.

\subsection{Step by Step Procedure for Proposed Method}

A step by step procedure of the proposed method can be stated as follows:

- Step1: Pairwise comparisons of criteria with respect to goal using the linguistic values given in Table1.

- Step2: Pairwise comparisons of alternatives with respect to criteria using the linguistic values given in Table1.

- Step3: Make the conversion of those linguistic values to triangular fuzzy numbers (TFNs) using Table1. One has to note that this study, due to its nature and structure as a marketing strategy selection, requires a more sensitive scale, rather than conventional scales used in most studies, in order to evaluate subjective expert judgments.

Table1. Linguistic values and values in TFN form.

\begin{tabular}{lc}
\hline Linguistic Values & TFN \\
\hline Very Low (VL) & $(1 / 2,1,3 / 2)$ \\
Low (L) & $(1,3 / 2,2)$ \\
Medium (M) & $(3 / 2,2,5 / 2)$ \\
High (H) & $(2,5 / 2,3)$ \\
Very High (VH) & $(5 / 2,3,7 / 2)$ \\
\hline
\end{tabular}

- Step4: Finding the weights using the geometric mean technique ${ }^{37,38}$.

- Step5: Calculate the final aggregated fuzzy scores for the alternatives as the fuzzy weighted sum of the relative priorities of the alternatives with respect to the problem's criteria.

- Step6: Rank the alternatives using the fuzzy metric distance method.

\section{Proposed Model}

When marketing their products firms need to create a successful mix of the right product, sold at the right price, in the right place and using the most suitable promotion. Resources spent on marketing mix elements can be organized in different proportions. What are meant by resources are not only the money but also the time and the effort. The proportions of these elements are concerned with effectiveness. The marketing strategy of a company is expected to analyze the environment, designing the fit between the company, its resources and objectives. While constructing the marketing strategy, the company must consider many factors and must be fast for the return of the investment. 
This model shows the criteria that are effective in marketing strategy decision process. It can be an additional tool for marketing decision makers. The objective of the model is to determine a marketing strategy for the company to launch the new product to the market and to weight the elements of the MM.

\subsection{The Alternatives of the Model}

Marketing mix elements are Philip Kotler's 4P of the marketing: Product, Price, Place and Promotion ${ }^{15}$. Each $P$ represents different strategies for the marketing of the new product and is vital for the success. It is a framework which helps to structure the approach to each market. The mix is a bundle of variables which are offered to the customer.

Product, perhaps the most important of the 4P's, is acquired by the customers via exchange to satisfy a need. Product consists of quality, variety, characteristics, options, style, brand, package, product service and all the other elements that reach the customer with the product.

Price, is basically about the charging of the product however, pricing is not that simple. Price should be considered with the segmentation and the positioning of the product because price always brings a classification to the product. Besides, pricing strategy proceeds with the product's life cycle. List price, discounts, allowances, payment periods, credit terms etc. should be considered throughout the process.

Promotion is the most ubiquitous element of a company's marketing strategy because promotional activities are necessary to communicate the features and benefits of a product to the company's intended target markets ${ }^{4}$. Advertising, sales promotion, personal selling, public relations are included in promotion.

Place, actually distribution, is about the availability of the product. Channels, coverage, locations, inventory, transportation, logistics, supply chain, retailers, supplier relations, vertical integration are distribution factors and are taken into account in place strategy.

This model aims to give percentages to these strategies, to show their importance and to help the company to decide how to make investment and how to give importance to these strategies. Consequently, the 4P's are the four alternatives of the model ${ }^{15}$.

\subsection{The Criteria of the Model}

Generating an appropriate marketing strategy is a long and delicate process which consists of analysis, segmentation, target market selection, positioning and building the MM. First, the company makes an analysis in detail to familiarize the market and the consumer. Then the company distinguishes the segments of the market and decides if it will serve all the market (mass marketing) or a precise segment of market. Market segmentation is the process of dividing the total, heterogeneous market for a product into several submarkets or segments, each of which tends to be homogeneous in all significant aspects ${ }^{14}$. One of these segments is selected as the target market and lastly the company creates a positioning with product factors, for example with the brand image or value.

In the model, all the factors that are effective while building marketing strategy in new product development process are determined and classified. All internal and external factors are examined, in order to adequately evaluate the MM decision; all the subcriteria which are substantial for the marketing strategy are concentrated under four critical criteria. These four major evaluation factors are company, market, consumer and product life cycle.

Company: Organizational relationships, management, organizational resources and organizational culture factors constitute the criteria. The quality of administration and the managers' know-how are the management factors. R\&D performance, technological advantages and the patents that the company has right to use, lastly the internal factors like financial resources of the company, scale economies with the flexibility of the capacity and the cost structure included fixed and operating costs are taken into consideration under the company criteria which may have a strong impact on marketing mix factors.

Consumer buying behavior: Researchers in marketing have studied most areas of consumer behavior including the impact of everything on how people behave and how they consume products. The consumers' behavior is noteworthy criteria for composing the MM. The 
company aiming to increase the sales should satisfy the consumer. After providing the customer satisfaction, the company creates a brand image supported by the brand reliability. With a right brand management the company may have successful product with a long life cycle which means a well sales figure.

Market: The choice of target market affects the mix. The mix must adapt itself to the market. Market criteria consist of market share, market/segment size, market growth rate and competition. Market share is an external factor for the company. Market/segment size is the number of consumers that exist in company's target market. Market growth rate is about the number of consumers that participate in the target market/segment in a unit of time. Competition is the number of competitors of the company in the market.

Product life cycle: A new product progresses through a sequence of stages from introduction to growth, maturity and decline. This sequence is known as the product life cycle. Product life cycle is one of the most widely known and respected of marketing planning tools ${ }^{4}$. It has a strong impact on the MM because every stage of the product life cycle needs its own marketing strategy, hence the MM.

For example, the promotion strategy of a product in its introduction stage should not be the same with a product in its mature stage. Since the strategies differ in different stages, it is an inevitable criterion for the MM (see Figure 2).

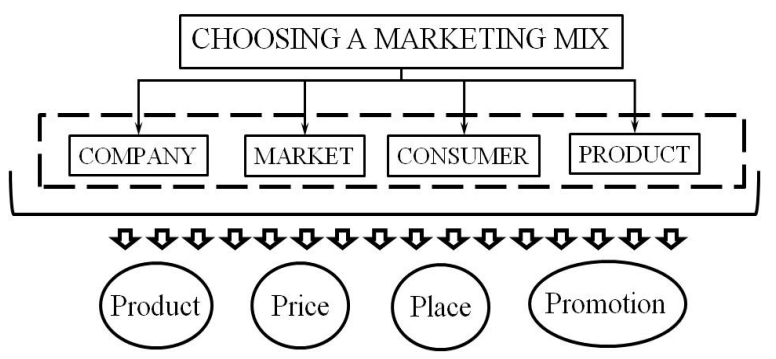

Fig. 2. Proposed Model

\section{Numerical Application}

The application of the proposed model will be carried on the launch market for a new product of a company producing fast moving consumer goods in the food sector where it serves for 40 years and holds second place in the market share.

The criteria and the alternatives of the model are weighed with the consensus decision given by a group of experts who are chosen by the company: two engineers from the production department, two managers from the marketing department and two customers of the company.

\subsection{Criteria Weighting}

Using the linguistic values given in Table1, criteria of our model is compared by the group of DMs with respect to the main goal.

Therefore, after performing the step1 of the proposed method, following comparisons are obtained:

Table2. Pairwise comparisons of criteria with respect to the goal.

\begin{tabular}{c|cccc}
\hline GOAL & Company & Consumer & Market & Product \\
\hline Company & - & & L & M \\
Consumer & $\mathrm{M}$ & - & $\mathrm{L}$ & $\mathrm{VH}$ \\
Market & & & - & $\mathrm{H}$ \\
Product & & & & - \\
\hline
\end{tabular}

These linguistic comparisons are going to be converted to TFNs using Table1 and the relative priority values or weights for the criteria will be detailed and calculated in Section 5.3.

\subsection{Evaluation of Alternatives with respect to Criteria}

Using the same linguistic values as in Section 5.1., pairwise comparisons of the alternatives with respect to each criterion of the model is performed.

Tables 3-6 show the pairwise comparisons of the alternatives with respect to the criteria of the proposed model (step2). Missing parts in the comparison matrices are filled using the following property for the pairwise comparison matrices (where $n$ is the dimension of the comparison matrix):

$$
a_{i j}=1 / a_{j i}, \forall i, j=1, \ldots, n \quad i \neq j
$$


Table3. Pairwise comparisons of alternatives with respect to Company.

\begin{tabular}{c|cccc}
\hline Company & Price & Product & Place & Promotion \\
\hline Price & - & & $\mathrm{M}$ & \\
Product & $\mathrm{M}$ & - & $\mathrm{H}$ & $\mathrm{M}$ \\
Place & & & - & \\
Promotion & $\mathrm{L}$ & & $\mathrm{M}$ & - \\
\hline
\end{tabular}

Table4. Pairwise comparisons of alternatives with respect to Consumer.

\begin{tabular}{c|cccc}
\hline Consumer & Price & Product & Place & Promotion \\
\hline Price & - & $\mathrm{M}$ & $\mathrm{H}$ & $\mathrm{M}$ \\
Product & & - & $\mathrm{H}$ & $\mathrm{VL}$ \\
Place & & & - & \\
Promotion & & & $\mathrm{H}$ & - \\
\hline
\end{tabular}

Table5. Pairwise comparisons of alternatives with respect to Market.

\begin{tabular}{c|cccc}
\hline Market & Price & Product & Place & Promotion \\
\hline Price & - & VL & M & \\
Product & & - & H & \\
Place & & & - & \\
Promotion & M & M & VH & - \\
\hline
\end{tabular}

Table 7. Pairwise comparisons and relative fuzzy weights for the criteria.

\begin{tabular}{c|cc|cc|ccc|ccc|ccc|cc|cc|c}
\hline $\boldsymbol{G O} \boldsymbol{A L}$ & \multicolumn{4}{|c|}{ Company } & \multicolumn{2}{c|}{ Consumer } & \multicolumn{3}{c|}{ Market } & \multicolumn{3}{c|}{ Product } & \multicolumn{2}{c|}{ Geom. Mean } & \multicolumn{2}{c}{$\begin{array}{c}\text { Relative Fuzzy } \\
\text { Priorities. }\end{array}$} \\
\hline Company & 1 & 1 & 1 & 0,4 & 0,5 & 0,7 & 1 & 1,5 & 2 & 1,5 & 2 & 2,5 & 0,88 & 1,11 & 1,35 & 0,17 & 0,25 & 0,38 \\
Consumer & 1,5 & 2 & 2,5 & 1 & 1 & 1 & 1 & 1,5 & 2 & 2,5 & 3 & 3,5 & 1,39 & 1,73 & 2,05 & 0,26 & 0,4 & 0,58 \\
Market & 0,5 & 0,7 & 1 & 0,5 & 0,7 & 1 & 1 & 1 & 1 & 2 & 2,5 & 3 & 0,84 & 1,03 & 1,32 & 0,16 & 0,23 & 0,37 \\
Product & 0,4 & 0,5 & 0,7 & 0,3 & 0,3 & 0,4 & 0,3 & 0,4 & 0,5 & 1 & 1 & 1 & 0,44 & 0,51 & 0,6 & 0,08 & 0,12 & 0,17 \\
\hline
\end{tabular}

SUM: $\quad 3,55 \quad 4,37 \quad 5,32$

\subsection{The Final Aggregation}

Once the conversion of these linguistic values are transformed to fuzzy numbers using Table1(step3), step4 is performed and fuzzy priority vectors of the criteria and fuzzy scores of the alternatives with respect to each criterion are obtained.
Details of these two steps are shown for the pairwise comparison of the criteria with respect to the goal in Table7.

The relative fuzzy priority weights for all the other pairwise comparison matrices are presented in Table8.

Table 8. Fuzzy weights.

\begin{tabular}{l||ccc|ccc|ccc|ccc}
\hline \multicolumn{1}{c||}{ CRITERIA } & \multicolumn{3}{c}{ COMPANY } & \multicolumn{4}{c}{ CONSUMER } & \multicolumn{3}{c}{ MARKET } & \multicolumn{3}{c}{ PRODUCT } \\
\hline $\boldsymbol{w}$ & 0,17 & 0,25 & 0,38 & 0,26 & 0,4 & 0,58 & 0,16 & 0,23 & 0,37 & 0,08 & 0,12 & 0,17 \\
\hline \hline ALT. & \multicolumn{1}{||}{} & & & & & & & & & & \\
\hline PRICE & 0,14 & 0,21 & 0,32 & 0,27 & 0,4 & 0,59 & 0,14 & 0,23 & 0,35 & 0,18 & 0,28 & 0,45 \\
PRODUCT & 0,28 & 0,41 & 0,58 & 0,15 & 0,24 & 0,37 & 0,16 & 0,24 & 0,4 & 0,1 & 0,15 & 0,24 \\
PLACE & 0,09 & 0,13 & 0,19 & 0,08 & 0,11 & 0,17 & 0,08 & 0,11 & 0,17 & 0,13 & 0,2 & 0,32 \\
PROMOTION & 0,17 & 0,25 & 0,38 & 0,16 & 0,24 & 0,4 & 0,28 & 0,42 & 0,6 & 0,23 & 0,37 & 0,56 \\
\hline
\end{tabular}

With step 5, the final aggregated fuzzy scores of the alternatives have been calculated by calculating the weighted sum of relative priorities of the alternatives with respect to problem's criteria. 
Then, for step 6, first using formula (2), the geometric centers of those fuzzy scores are found, then, using formula (3), the distances from the origin is calculated. Finally, from those scores, percentages have been found by normalization. These values and the final aggregated fuzzy scores for the alternatives can be observed in Table9.
Criteria Weighting 4 P Planning According to the result of the model, the company must spend the following percentages of the total investment (financial resources, effort, etc.) for 4P's :

- $25.8 \%$ to the product itself,

- $26.8 \%$ for the price strategy,

- $27.3 \%$ for the promotion and

- $20.1 \%$ for the place/distribution.

Table 9. Final Aggregation.

\begin{tabular}{|c|c|c|c|c|c|c|c|c|c|c|c|c|}
\hline \multirow{2}{*}{$\begin{array}{c}\text { FINAL } \\
\text { AGGREGATION } \\
\end{array}$} & \multicolumn{3}{|c|}{ PRICE } & \multicolumn{3}{|c|}{ PRODUCT } & \multicolumn{3}{|c|}{ PLACE } & \multicolumn{3}{|c|}{ PROMOTION } \\
\hline & 0,13 & 0,3 & 0,67 & 0,12 & 0,27 & 0,62 & 0,06 & 0,13 & 0,29 & 0,13 & 0,3 & 0,69 \\
\hline $\begin{array}{c}\text { DISTANCE TO } \\
\text { ORIGIN }\end{array}$ & \multicolumn{3}{|c|}{0.494} & \multicolumn{3}{|c|}{0.475} & \multicolumn{3}{|c|}{0.369} & \multicolumn{3}{|c|}{0.502} \\
\hline PERCENTAGES & \multicolumn{3}{|c|}{26.80} & \multicolumn{3}{|c|}{25.80} & \multicolumn{3}{|c|}{20.10} & \multicolumn{3}{|c|}{27.30} \\
\hline
\end{tabular}

\section{Conclusions}

The reason that the majority is dedicated to the promotion is that the company is making category extension. As the product has new brand, the company must give significant weight on promotion activities. Therefore, it is normal that the share of the promotion will have a much higher percentage than others. It is observed that the price has a higher percentage compared to the product and distribution. Pricing is a really important aspect of a business and is a crucial component of the marketing mix. The right pricing can help to achieve greater sales and greater profitability, whereas poor pricing can leave the products failing to sell or even to sell too cheaply.

As the company must give a new product, the share of the product is higher than this of the distribution. The company will conduct $R \& D$ and market research; it will create a new production line, new brand and will waste time and money in the process of decision.

The importance of the distribution is lower than others because of the current presence of a distribution chain and the absence of the need to invest more just for this new product.

These four P's are the parameters that the marketing manager can control, subject to internal and external constraints of the marketing environment. The goal is to make decisions that center the four P's on the customers in the target market in order to create perceived value and generate a positive response. The marketing mix framework was particularly useful in the early days of the marketing concept when physical products represented a larger portion of the economy.

Today, with marketing more integrated into organizations and with a wider variety of products and markets, it is useful to extend the study by proposing a fifth $\mathrm{P}$, such as people, packaging, process etc. Today however, the marketing mix most commonly remains based on the 4P's. Despite its limitations and perhaps its simplicity, the use of this framework remains strong and this study has been organized around it.

\section{Acknowledgements}

This research has been financially supported by Galatasaray University Research Fund.

\section{References}

1. Cravens, D. W. (2000). Strategic marketing (6th ed.). Boston: Irwin/McGraw-Hill.

2. Chen, H. H., H.I. Lee, A., \& Tong, Y. (2006). Analysis of new product mix selection at TFT-LCD technological conglomerate network under uncertainty. Technovation, 26(11), 1210-1221

3. Liao, C.-N. (2011). Fuzzy analytical hierarchy process and multi-segment goal programming applied to new product segmented under price strategy. Computers \& Industrial Engineering, 61(3), 831-841.

4. Ferrell, O. C., \& Hartline, M. D. (2011). Marketing strategy (5th ed.). Australia ; Mason, Ohio: SouthWestern Cengage Learning.

5. Kotler, P., \& Armstrong, G. (2012). Principles of marketing (14th ed.). Boston: Pearson Prentice Hall. 
6. Denguir-Rekik, A., Montmain, J., \& Mauris, G. (2009). A possibilistic-valued multi-criteria decision-making support for marketing activities in e-commerce: Feedback Based Diagnosis System. European Journal of Operational Research, 195(3), 876-888.

7. Lin, C.-T., Lee, C., Wu, C.-S. (2009). Optimizing a marketing expert decision process for the private hotel. Elsevier - Expert Systems with Applications , 56135619.

8. Wu, C.-S., Lin, C.-T., Lee, C. (2010). Optimal marketing strategy: A decision-making with ANP and TOPSIS. Elsevier - Int. J. of Production Economics , 190-196.

9. Li, S. L., \& Li, J. Z. (2010). AgentsInternational: Integration of multiple agents, simulation, knowledge bases and fuzzy logic for international marketing decision making. Expert Systems with Applications, 37(3), 2580-2587.

10. Wierenga, B. (2011). Managerial decision making in marketing: The next research frontier. International Journal of Research in Marketing, 28(2), 89-101.

11. Tsai, W.-H., Chou, W.-C., Leu, J.-D. (2011). An effectiveness evaluation model for the web-based marketing of the airline industry. Expert Systems with Applications, Article in Press.

12. Liao, C.-N. (2011). Fuzzy analytical hierarchy process and multi-segment goal programming applied to new product segmented under price strategy. Computers \& Industrial Engineering, 61(3), 831-841.

13. Wang, Y. L., \& Tzeng, G. H. (2012). Brand marketing for creating brand value based on a MCDM model combining DEMATEL with ANP and VIKOR methods. Expert Systems with Applications, 39(5), 5600-5615.

14. Stanton, W. J. (1981). Fundamentals of marketing (6th ed.). New York: McGraw-Hill.

15. Kotler, P. (1999). Le Marketing Selon Kotler. Paris : Village Mondial.

16. Freter, H., \& Baumgarth, C. (2004). Marktorientierte Unternehmensführung : Grundkonzepte, Anwendungen und Lehre : Festschrift fur Hermann Freter zum 60. Geburtstag. Frankfurt am Main; New York: P. Lang.

17. Bradley, F. (2003). Strategic Marketing : In the Customer Driven Organization. Chicester, West Sussex, England ; Hoboken, NJ: J. Wiley

18. McCarthy, E. J. (1960). Basic marketing, a managerial approach. Homewood, Ill.,: R.D. Irwin.
19. Saaty, T.,L., The Analytic Hierarchy Process, McGraw Hill, New York, (1980).

20. F.-H. F. Liu, H.L. Hai, "The Voting Analytic Hierarchy Process Method for Selecting Supplier", International Journal of Production Economics, vol.97, no.3, pp.308 317, (2005).

21. T. Omasa, M. Kishimoto, M. Kawase, K. Yagi, "An attempt at decision making in tissue engineering: reactor evaluation using the analytic hierarchy process", Biochemical Engineering Journal, vol. 20, no.2-3, pp.173-179, (2004).

22. İ. Ertuğrul, N. Karakaşoğlu, "Performance evaluation of Turkish cement firms with fuzzy analytic hierarchy process and TOPSIS methods", Expert Systems with Applications, vol.36, no.1,pp.702-715, 2009.

23. E. Heo, J. Kim, S. Cho, "Selecting hydrogen production methods using fuzzy analytic hierarchy process with opportunities, costs, and risks", International Journal of Hydrogen Energy, vol.37, no.23, pp.17655-17662, (2012).

24. İ. Korkmaz, H. Gökçen, T. Çetinyokuş, “An analytic hierarchy process and two-sided matching based decision support system for military personnel assignment", Information Sciences, vol.178, no.14, pp.2915-2927, (2008)

25. L. Wang, J. Chu, J. Wu, "Selection of optimum maintenance strategies based on a fuzzy analytic hierarchy process", International Journal of Production Economics, vol.107, no.1, pp.151-163, 2007.

26. Y.C. Erensal, E. Albayrak, Successful adoption of macroergonomics in Manufacturing: Using a multicriteria decision-making methodology - Analytic Hierarchy Process, Human Factors in Ergonomics in Manufacturing, vol.14, no.4, pp.353-377, 2004.

27. van Laarhoven, P.J.M., Pedrycz, W., (1983). A fuzzy extension of Saaty's priority theory. Fuzzy Sets and Systems 11, 229-241.

28. Buckley JJ. (1985). Ranking alternatives using fuzzy numbers. Fuzzy Sets Syst; 15(1):21-31.

29. Stam, A., Minghe, S., Haines, M., (1996). Arti.cial neural network representations for hierarchical preference structures. Computers \& Operations Research 23 (12), 1191-1201. 
30. Chang, D.Y., (1996). Applications of the Extent Analysis Method on Fuzzy AHP. European Journal of Operational Research 95, 649-655.

31. Ching-Hsue, C.,(1997). Evaluating naval tactical missile systems by fuzzy AHP based on the grade value of membership function. European Journal of Operational Research 96 (2), 343-350.

32. Cheng, C.-H., Yang, K-L., Hwang, C-L., (1999). Evaluating attack helicopters by AHP based on linguistic variable weight. European Journal of Operational Research 116 (2), 423-443.

33. Zhu, K-J., Jing, Y., Chang, D-Y., (1999). A discussion on extent analysis method and applications of fuzzy AHP. European Journal of Operational Research 116, 450-456.

34. Cheng, C.H.,(1998) A new approach for ranking fuzzy numbers by distance method, Fuzzy Sets and Systems, 95, 307-318.

35. Murakami, S., Maeda, S., Imamura, S., Fuzzy Decision Analysis on the Development of Centralized Regional Energy Control System, IFAC Symposium on Fuzzy Inform. Knowledge Representation and Decision Anal., pp.363-368, 1983.

36. Lee, E.S., Li, R.L., Comparison of fuzzy numbers based on the probability measure of fuzzy events, Computer \& Mathematics Application, Vol.15, pp. 887-896, 1988.

37. Buckley, J.J., Fuzzy Hierarchical Analysis, Fuzzy Sets and Systems, 17, 233-247, 1984.

38. Mikhailov, L., Deriving priorities from fuzzy pairwise comparison judgments, Fuzzy Sets and Systems, 134, 365-385, 2003. 